\title{
An Intercultural Adaptation of The Sound of Music on a Nigerian Stage
}

\author{
Olympus G. Ejue, Barth Oshionebo \& Isaiah Ilo \\ http://dx.doi./org/10.4314/ujah.v19i1.10
}

\section{Abstract}

The objective of this paper is aimed at appraising the value of intercultural theatre and at the same time striving to understand the implications of adapting a classical film to a live theatre performance. It is not an overstatement to say that a film like The Sound of Music with its rich techniques, plot, scenery and directorial approach will not only create audience appeal, but that its immediacy of themes, popularity and box-office success can attract any adaptor. The study which uses literary and artistic methodology observes that the prospect of adapting film to live theatre performance goes beyond interpreting the film as it were, because a lot of artistic manipulations and exploration of new techniques to serve as fecundity for live stage directing will be required. Therefore, through a stylized approach aimed at creating originality, theatricality and style with respect of verisimilitude, the adaptor director created on stage sheer theatrical brilliance, beauty, excitement and theatrical imagination. The performance suggests that the process of transcreation without tempering with the spine or thematic preoccupation of the film is simply of style of crossing borders of culture, language, continents and genre. The live theatre director makes a theatrical entity of the entire production with an intuitive perspective to foster global cultural exchange and interaction. The paper concludes that; using intercultural theatre approach which allows for mixing cultures 
and subculture in theatrical performance can be in more ways than one promote cultural tolerance and peace.

\section{Introduction}

Theatre directors have different obligations in terms of production styles, depending on the theatre they are operating from. This is taken from the point of view that; the commercial, the non commercial, the community and literary/educational theatres all have several goals and obligations to attain. For example, in the commercial theatre, the director must attract sufficient financial gains to the box-office.

The literary or educational theatre director would tend to align his theatre with the phenomenon of a teacher who creates opportunity for team work, self-discipline and providing a sense of responsibility through a rounded dramatic production. Indeed, "The educational theatre director holds in his hands the great opportunity of helping his students to develop physically, vocally, intellectually, emotionally, culturally, and socially" (Wright, 1959: 132). From the foregoing, we can see and understand that the theatre as an institution should represent not only the best in type, style and structure, but from that which is classic even as film, and has a popular dramatic material and appeal to the Nigerian live theatre audience. This will as a matter of fact, help to build an audience that would appreciate live theatre even in the future.

The adaptation of The Sound of Music for the Nigerian stage through a directorial and artistic expression was approached from epistemological, analytical and intuitive perspectives to foster global cultural exchange and interaction. This is because, over the centuries theatre has proven to be a synthesis of the arts, that is capable of harnessing the philosophy of art of specific peoples and 
regions in order to unravel their relationships and groups. It becomes pertinent therefore, to reminiscence on Bewaji's claims which "presumed that every attempt to create works of art is an expression of culture in the cognitive and intellectual sense" (1). In this regard, the stage performance did not fail to recognize the critical philosophical implications of the artistic and cultural objects entrenched in the film. Arising from this contextual analysis of the film itself, its interpretation on a stage medium also took cognizance of creating meaningful stage pictures and movements; laying emphasis on rhythm, tempo and space as well as revealing a balance of empathy and aesthetic distance in the play to suit the Nigerian audience appeal.

Besides all these, the adapter envisaged that, the art of successfully adapting the film for stage would necessitate possessing certain basic theatrical attributes and/or qualities ranging from understanding the film director's approach, availability of actors to play on stage, live audience appeal, understanding the script and how to realize it on stage. This essence, which has positioned the theatre as a composite art from which essential dramatic characteristics intermix, whether from film to stage or vis-a-visa to unite or cause a theatrical experience upon which meanings can be derived must be taken seriously by the stage director.

\section{The Stage Director and the Theatre}

Beyond the artistic temperament, the production philosophy and professional inclinations of a particular director, the role of the director remains the same and every theatre production directs its focus on reaching the final destination of theatre product, the audience, in a language and aesthetic particulars they can assimilate (Inyang, 2013: 280). 
The prospect of directing on the Nigerian stage goes beyond script interpretation to a much more artistic inventiveness of manipulating the various theatre components with a view to achieving a greater aesthetic value in a performance. The theatre is a place where the relationship the director has with the playwright, actors and other members of the production crew is artistically harmonized and heightened with specific 'stage sense' to enhance the thematic thrust and mood of the performance. As an artist, the director draws from different sources to whet his/her creative hunches depending on the type of theatre the director is operating from.

However, it is true that, not many stage directors understand the charges of unifying a visualization within the foundation upon which an adequate interpretation is given, taking cognizance of his/her chosen style, audience appeal and the different types of stages available to him/her to graphically actualize his/her vision. This is so because, the stage-type can give or condition particular type of blockings or interpretations in a performance. Just like playwrights find it necessary to make clear their creative ideas; stage directors, whether interpreting a new script or adapting and reinterpreting an old one, should be able to exude a certain level of understanding in which "the director must be able to envision the play's atmosphere or mood and know how to actualize it in terms of design and theatrical space" (Nyatuame and Bello, 2013:63.)

In this regard, one often views a stage performance as a director's hole-in-the-wall upon which the actors, costumiers, designers and technicians, and most especially the audience have a peep into a unified vision within the finished production. The basic determining factor in the relationship between the stage director and the theatre is in the method or/and directorial concepts of 
creating the locale upon which the dramatic action is situated with all the several performers inhabiting it. This is important because, one of the greatest tasks a director faces, is in how he/she intends to give meaning and steer the process of conceptualization in a performance. Thus, the director sees theatre as not just a vehicle for communication, but as a place whereby his experiential applications of approaches are factored in based on his relationship with his audience or with the theatre's relationship with its patrons. In other words, the ideology binding such a theatre must be well crafted to suit the motif and imaginative spirit for which interpretations for performances are laced. The reason is that; every theatre has its own admissible prescription in terms of style, quality, audience appeal and aesthetics which a director must strive to bring about. It is a display place where the director's personal style-insignia is reflected in a performance

\section{Intercultural Theatre}

Intercultural theatre also known as cross-cultural theatre has come a long way transcending recent history. It is a kind of theatre creativity that enables theatrical performances from foreign cultures to be performed in such a way that can be appreciated and appeals to a wider range of local audience meaningfully. (Pavis, 1996:58)

As the name implies, Intercultural theatre involves the mixing and matching of cultures or subcultures in theatrical performance in order to appeal to a wider range of audience meaningfully. The first recognized and successful intercultural production was Peter Book's "Mahabharata" and ever since then the trend has evolved and become popular with many government and cultural institutions that actively sponsor such productions in order to push the boundaries of inter-cultural sense and to promote 
cultural tolerance and peace. There are three major types of intercultural theatre:

1. Imitational theatre: The imitational theatre is intended for audience who are from the same culture, or a foreign audience with different cultures. The actors who perform usually come from the same cultural background, for example, Yoruba actors, or from a very diverse foreign cultural background, for example, India.The production may imitate foreign styles, for example Japanese theatre; the production procedures may introduce new techniques, example Meyerhold's Bio-mechanics style of acting, or style of presentation for a group of actors from various cultures or same culture. The production may include foreign languages, costumes, scenes, themes, and other aspects.

2. Adaptive theatre: The adaptive theatre encompasses two types of intercultural theatre. This norm is considered to represent what the audience of a certain culture expects or has typically been exposed to.

i. Adapts to the norm: This is a traditional style of production that has been consciously adapted to fit with the cultural expectations of the intended audience of another culture. For example, a performance of "Hamlet" adapted and given a Nigerian coloration in which the English culture that is depicted in the play, is substituted for a Nigerian one in order to appeal to the Nigerian audience.

ii. Adapts away from the norm: In this case, the original culture dominates but it borrows foreign elements to enlarge the range of expression. This indirectly means that the dominating culture owns the original performance, but 
in an attempt to make it more acceptable or understood by a foreign culture, it borrows foreign elements. For example a performance of Ovoronwem Nogbaisi in a theatre in England. It might need to adapt to the environment by using possibly English songs and scenery during performance.

3. Universal Theatre The universal theatre just as the name implies seeks to be recognized and accepted by audience members from a wide range of cultural backgrounds. The themes mostly treated in such performances are usually universal in nature in order to be relevant to as many cultures as possible. For example, the theme of love is one that almost every culture can relate to.

There are, however, further sub-division of intercultural theatre. Because the efforts to promote intercultural theatre were mostly of Europeans or Americans, English language is the main medium of communication for knowing, acknowledging, debating, reasoning, considering, teaching, learning, writing, speaking, adapting, translating or transforming the one culture to the other culture in large contexts as in detailed micro-contexts. Some of the practitioners of intercultural theatre are Peter Brook, Robert Wilson, Jerzy Grotowski, and Philip Zarilli.

\section{Adapting The Sound of Music for Stage}

The Sound of Music is a 1965 American musical drama film produced and directed by Robert Wise, and starring Julie Andrews and Christopher Plummer. The film itself is an adaptation of the 1959 Broadway musical The Sound of Music, composed by Richard Rodgers with lyrics by Oscar Hammerstein II. The film's screenplay was written by Ernest Lehman, adapted from the stage musical's book by Howard Lindsay and Russel Crouse. Based on 
the memoir The Story of the Trapp Family Singers by Maria Von Trapp, the film is about a young Austrian woman studying to become a nun in Salzburg in 1938 who is sent to the villa of a retired naval officer and widower to be governess to his seven children. After bringing love and music into the lives of the family through kindness and patience, she marries the officer and together with the children they find a way to survive the loss of their homeland through courage and faith.

Adaptation means snooping into an original work of art by way of adjusting the original version with an ultimate intent towards creating more appeal and audience acceptability. In a way, adaptation from film to stage through a process of reworking and/or changing to suit a particular condition(s) will merely be a re-invention of the wheel of theatre practice. It is an exploration of new grounds to serve as an emergence of the fecundity of stage directing within the conceptualized film medium of telling a story. It is some sort of a marriage in which "film is heavily indebted to the stage for its personnel and technique" (Ekwuazi qtd in Ejue 2003:168). Little wonder therefore, that for some arguable reasons, most big names in the stage medium got enticed in more ways than one to the film medium. This underscores the point that both media could complement each other.

However, the process of adaptation here is to arouse a robust dramatic expression that is understandable, simple, exciting and captures succinctly the delicate shadings and nuances akin to the Nigerian audience sensibilities. Common sense has shown that every work of art in whatever medium has its creator who through certain artistic inspiration most times takes a swipe at society's events and their relationship with human beings. This becomes an original source material through which a theatre director for instance, is predisposed to modifying its content, either 
historically, thematically, or aesthetically so as to suit new conditions in terms of new platform, environment, greater appeal and perceived wider audience patronage.

Furthermore, the word 'adaptation' as a creative dramatic genre is more common with the idea of transposing of new plays from older ones. To Yerima (2003: 119), "adaptation suggests no more than one playwright taking another playwright's play and modifying it." However, adaptation in directing goes beyond certain principles as there are rules and end results that should be observed particularly when evaluating a film's storyline alongside the director's approach with a view to modifying and/or transposing same on a live stage. A critical appraisal of the filmThe Sound of Music in terms of techniques, plot and directorial approach, did not only create appeal and interest for this adapter, but the immediacy of the themes and the film's dramatic accomplishment even in terms of box-office success impacted a great deal on his artistic psyche.

In this context, the adapter stage director took cognizance of the period of the setting; themes and sub-themes; the names of people, places and titles; the context in which the story evolved; and perhaps a twist in the story in order to recreate the on-going issues in the Nigerian environment in order to bring positive meanings nearer to the immediate local audience. With all these in mind, the adapting stage director for The Sound of Music ensured for example that; the setting moved from Salzburg-Austria to Abuja-Nigeria with the characters' names and titles all changed to English names popular in Nigeria. For example, the names of the seven children of the Captain were changed thus; Marta to Helen, Friedrich to David, Louisa to Jane, Kurt to Peter, Brigitta to Mary, Liesl to Martha, Gretl to Evelyn. We see an exchange of the German names with English also used in Nigeria. It was clear on 
stage that some of the characters in the film inhabit the adapting director's imagination, hence he used them to avoid sterile polemics, especially in a country where people are terribly susceptible to ethnic misinterpretations. For example, an ethnic name given to a villain could exemplify that members of such ethnic groups are villains. Also, the period of setting is altered from 1938 Salzburg to 2017 Abuja given the new audience, their appeal and even prevailing circumstances of the time in the Nigerian state.

Most of the European style of music, songs, and dances in the film were spiced up with selected harmonic texture of popular Nigerian music and songs with the intent of defining the Nigerian music world on stage. In fact, the vocabulary of these songs and their popularity conjured an authentic idiomatic melody and rhythm of the Nigerian people. Nketia (2001:6), attests to the importance of music as a language of communication. He states that; "a well-crafted music could reflect not only a person's aesthetic sensibility but the quality of his mind or his modes of musical thoughts." This imaginative response was to create and accommodate the cultural, social, political and economic circumstances through this dynamic Nigerian flavour of songs and music profile. Maria's singing of Do-a-Deer, a Female-Deer to the children in pidgin was thrilling and creative. Here are both the original and adapted versions of the song:

Doe.... a deer, a female deer Ray... a drop, of golden sun Me... a name, I call myself Far... a long, long way to run Sew... a needle pulling thread La... a note to follow sew
Doe...my dear, you don do well

Ray...na dey light wey dey for sun Me...na dey name, I dey call myself Far...na dey only way to run

So....my story never end

La...na to follow sew 
Tea... a drink with jam and bread Tea...na drink with egg and bread That will bring us back to If you mix-am well do...oh oh oh do do do do do do!

In some cases like, beautifying the wedding venue which was in mime by the Reverend Sisters in readiness for Maria and the Captain; the scene beheld a lot of trumpeting and Nigerian drumming to complement the Nigerian praise-and-worship songs like; 'To God be the Glory', 'Showers of Blessings', 'Chineke idi mma', 'Kosoba bire', 'Jehova has the final say,' et cetera. In fact, most of the classical musicals in the film were replaced with Nigerian songs, even those rendered in pidgin and vernacular. Some of the songs deployed for the stage performance included Phyno's Ogene; Flavour's Ada Ada; Fela's Wahala; Falz and Simi's Soldier, Victor Olaiya and 2face Idebia's Baby Jowo, et cetera. Adapting the original film for stage, therefore, saw all of these songs and even dance steps changed to suit the Nigerian audience sensibilities, but for want of time and space, we may not be able to convey all the altered versions in this paper.

Unlike the final scene, where the film recorded the Von Trapp family after performing alone in a choral festival at the Salzburg Hall, were escaping from 'forced Naval service 'through the mountains, the stage version recorded the family performing at the Eagle Square in what looked like an Abuja carnival, alongside other Nigerian musical icons in some sort of competition, before escaping rather through back stage. This of course, is to avoid the cumbersomeness of creating those mountains and valleys on stage with particularly slim budget and poor facilities for the production. There is no gainsaying here that; "Film is often called a director's medium, because the director has a great deal of creative control" (Downs, Wright and Ramsey, 2013:29).Simply put; the film 
director has more options, hence, he can shoot a scene repeatedly and therefore, control exactly what the audience would see through his shot-by-shot technique.

\section{Directing The Sound of Music on Stage}

The effective power of music, its intriguing features and the intercultural elements imbedded in the film would have prompted its adaptation on the live stage of the Open Air Theatre, University of Abuja. This is also bearing in mind that music when sung by a particular actor has a much more memorable effect on an audience, than when that same actor engages in the use of words alone. The Sound of Music on the Nigerian stage engaged a revolutionary directorial process of 'transcreation' or 'translation - adaptation' without misplacing completely 'the spine' and/or thematic preoccupation of the film. It is a style of crossing borders of culture, language, continents and genre by means of a stage medium that reveals the powerful magic of the theatre in general, and that of the film in particular.

The director's interpretative paradigms bothered on the intercultural context of creativity and by extension the circumstances in the film that are universal in human cultures. For example, love, sacrifice, marriage, and destiny which the film reflects as its major thematic preoccupation appear also on the Nigerian stage as not only applicable to Austria alone. However, the process of directing The Sound of Music on stage justified a skipping over of certain scenes in the film due to exorbitant cost of stage paraphernalia. This was also coupled with, not just the anticipated technicalities involved in handling those scenes on stage, but in the film director's use of very rich and natural décors and sceneries like mountains, hills, valleys, rich flower-beds and 
gardens, flowing-streams and lakes et cetera to make striking statements about the background and picturesque view of the people in the film. This is true because, according to Cameron and Gillespie (2004:185), "Sitting in the modern theatre, we sometimes take the presence of scenery so much for granted that it is easy to forget that theatre does not have its roots in either spectacular effects or localizing settings."

Hence, realizing all of such sceneries on stage was an uphill task particularly since the Open Air Theatre, like most literary theatres in Nigeria, epitomizes 'the poor theatre' in terms of lack and want of basic production facilities. After all, "The fact of our third world status with its attendant poverty has not spared our educational institutions" (Johnson, 2003, 95-96).Nonetheless, in the wisdom of emphasizing these beauty of grand action on stage, the director reasoned in the line of Eghagha (2002: 71) that; "Anyone who is familiar with aesthetics of spectacle must be conscious of the argument against the naturalists' spirit of cluttering the stage with props that are relevant or irrelevant in order to have a successful production in a house of phantoms." Therefore, in trying not to down-play the dynamics and aesthetics of spectacle in the film, the stage director paid attention to the sensibilities of the audience through a spirited acting process of deploying defined movements, including dance steps, gestures, voice projection and general body carriage of the actors. In other words, the intent was to forge out of that 'theatre of poverty' some recognizable aesthetics in terms of theatricalities; what Johnson coinedas 'The Aesthetics of poverty'.

Conjuring the esthetic power and effect of an opening glee in any performance, the stage play-The Sound of Music with Nigerian Spices opens with the humming and eventual singing together of the prominent Georg Friedrich Handel's Hallelujah 
Chorus by the entire cast on stage. This opening heralds the audience into a conventicle setting of religion and a theatre that is musical. The filing-out of the large choir simply left behind the Rev. Mother and some sisters in a simple abbey setting with just a table and two chairs. It was a search for the whereabouts of Maria through the following songs:

Rev. Mother: She climbs a tree and scrapes her knee, Her dress has got a tear, She waltzes on her way to mass and whistles on the stair And underneath her wimple she has curlers in her hair, I have even heard her sing in the abbey.

All Sisters: She's always late for chapel but her penitence is real,

She's always late for everything except for every meal, But I very firmly feel she's not an asset to the convent How do you solve a problem like Maria?

How do you catch a cloud and pin it down?

How do you find a word that means Maria?

A flibbertigibbet - a will -o '- the wisp - clown

Many a thing you know you'd like to tell her

Many a thing she ought to understand

But how do you make her stay and listen to all you say?...

The Reverend Mother placed at stage centre, moving diagonally to the left and right, and the eight Sisters, four on each side of the stage in a symmetry style, performed this musical dialogue with movements that warranted them to crossways as they sang their lines, yet maintaining good stage picturization and balance. More interesting was the director's use of some elements of African music patterns, where these Sisters and their several parts produced 
the same melody at different pitch levels and in certain time, a series of parallel chords. In terms of rhythm and percussion the director reflected a close link between music and dance as observed in the body language of the Sisters. Through the use of log drums, flutes, rattles and other idiophones, the drummers, trumpeters and other musicians added their voices to that of the actors on stage by imitating the rhythms and pitch fluctuations of words to ginger the desired movement on stage. This Nigerian flavour in the original song got the audience more immersed in the performance.

The film director's act of characterizing Maria in terms of the way she thinks, feels and behaves leaves one thinking of Maria as having a split personality. For example, she was depicted in the film as a misfit for the convent, yet as someone with the prowess of a nanny that can take care of a widower and his seven children. For that reason, the stage director did a guesstimate on Maria's state of mind at the point she was preparing and psyching herself up to meet with the Captain and his children. Consequently, she was portrayed on stage as one bestowed with certain mannerism and motives likened to that of somebody having psychosomatic symptoms. Accordingly, she arrives at the stage in search of the Captain's house with a mixed feeling of despairing and audaciousness. Darey art Alade's music-Pray for $\mathrm{Me}$ by the orchestra captures the mood and inner thoughts of Maria at this point. They sang thus:

Wake up one Sunday morning

Told my dad I was leaving for the city

He said, life in the city is unbelievable

I know I could get lost

Pray for me

Gbadura fun mi 


\author{
Pray I find my way \\ $K$ 'oribamise \\ Oh forgive me father but I got to take a chance \\ Oh I'm already gone so just, pray for me
}

The sub textual communication here basically points at what might befall Maria at the Captain's house, having been told of his regimented life style. She reflected this through a lot apprehension in her movement and mannerism, as we see her press the door-bell and the sound of it jolted her and provoked an unprecedented sign of the cross from her.

Singing and playing musical instruments are socio/cultural activities that permeate the psyche and life style of most Nigerians. Hence, an inclusion to the stage performance, was the introduction of an orchestra situated just at the apron of the stage to hitherto offer an ancillary voice to the actor(s) singing on stage. There were short musical phrases from the orchestra, repeated to capture the spirit behind some of the lines rendered by certain actors on stage. This is in line with the director's reasoning that; all through history, singing has been the most pervasive and familiar way of creating music that could capture the audience's appeal particularly if heightened. Kamien, (2006:11) seems to agree with this claim. He asserts that; "Singers seem to have had a magnetic appeal, and the exchange between singer and audience contains a bit of magic - something direct and spellbinding." The situation here can be liken to that of the chorus in the ancient Greek theatre, who acted, served as interludes and gave opinions on the dramatization on stage using music, song and dance. Therefore, focusing on the functionality of music as a performing art in theatre production, performance of The Sound of Music on stage was characteristically of a call and response style, where the catchphrases of the soloist 
are repeatedly answered by those of the orchestra. This is in line with Brown's thought that; "Music that is played or sung is signaled by stage directions, and its contribution to how the play works is usually limited to particular moments" (45). Despite this limited allotment, the response from the audience with regards to the musical component infused in the play was awesome. This is particularly so that; the interjections were carefully designed with a view to determining the pace of the play in terms of scene change, tempo, and even the mood of the play on stage.

Worthy of mention here is that; the director employed the "straight-take method" which did not require any form of back-out or fadeout in between scenes in the performance. In other words, this directorial technique required all scene changes done in the full glare of the audience with synchronized sound, music and songs. It is a situation whereby, at the end of every scene, the actors on stage vacate the stage carrying along with them props and other stage paraphernalia not necessary for the next scene. Notwithstanding, the essence of light and its effect to not only interpret the mood and tone of the performance, but in describing moments of suspense, tension, and relaxation was deployed and fully integrated into the spirit of the performance. Bowskill's view on the function of light in a performance is apt.

He says: "lighting is probably one of the most singular effective devices available to the designer and director. Its impact on mood and atmosphere is well known." Reflecting on the stage performance, a particular scene captured the Captain's frame of mind through the hues of colours spotlighting him with his right knee bending and stretching out his right hand towards Maria as if to say, 'would you marry me?' To the audience, his actions demonstrated his sense of responsiveness as a human being and the way he felt at that particular time in his life. 
Added to this, is the use of costume which the director made conscious efforts not to deviate completely from the ones used in the film. For the Reverend Sisters and the Captain's children, it was a near replication of how the actors were costumed in the film. This was not in any way to undermine the adaptation process, but to still retain a certain level of the film director's concept which is expected to provoke a sense of belonging in terms of culturalexchange between the Europeans and the Nigerian audience. For example, the scene with Maria and the children returning from an outing had everybody costumed in Nigerian linen material. In fact, Maria wore a 'made-in-Nigeria' blouse sewn from indigenous textile material. The uniform worn by the children typified a school uniform in a Nigerian secondary school. While the party scene saw a matching of cultures through costumes as local 'ankara' textile materials were used to make waist-coat suits and trousers for the actors. They were some who wore the traditional Hausa 'agbada' and cap; while others were costumed with the Igbo royal jumper with a red cap to match, Efik and 'Niger-Delta outfits just to portray the Nigerianness of the play.

\section{Conclusion}

In this paper, we have tried to examine adaptation as a process and the dynamics and technicalities that can foster good theatre especially as an adapter from the film medium to live theatre staging. It is clear that the twenty first century Nigerian theatre director(s) should not only see himself as saddled with the responsibility of artistically analyzing a text for performance, but that; he could also be faced with the task of employing the technique of transcreation of a film onto a stage performance. It is on the strength of this that we witnessed the entire stage 
performance of The Sound of Music embellished with a combination of indigenous musicality and drama in terms of spatial movement, sound, music, songs, spoken dialogue, miming, acting, and dance. It is worthy to note that; eclecticism as a conceptual approach to the performance allowed for mixing styles and variety of theatre elements in the making of inner connections and the presentations of interculturalities through the actions of the actors on stage.

Considering further the process of cross-cultural communication, the adaptor director was simply not interested in replicating the film in its exactitude on stage; rather he engaged the film as an inspiring material that can be explored and staged with an increased suitability to capture the sensibilities of the Nigerian live theatre audience. Indeed, the directorial approach revealed that the story of a musical theatre as experienced in The Sound of Music is somewhat emotional in content, tone, pathos, love, anger, etc as reflected in the Nigerianized adaptation.

Olympus G. Ejue

Department of Theatre Arts

University of Abuja, Abuja

\section{Barth Oshionebo}

Department of Theatre Arts

University of Abuja, Abuja

\section{Isaiah Ilo}

Department of Theatre Arts University of Abuja, Abuja 


\section{References}

Bowskill, Derek. Acting and Stagescraft Made Simple. London: W.H. Allen, 1973

Brown, John Russel. What is Theatre? An Introduction and Explanation. Boston: Focal Press, 1997

Cameron, Kenneth $\mathrm{M}$ and Gillespie, Patti P. The Enjoyment of Theatre. Boston: Pearson Education Inc, 2004

Downs, William Missouri, Wright, Lou Anne and Ramsey, Erik. The Art of Theatre: Then and Now. United State: Wadsworth, Centage Learning, 2013.

Eghagha, Hope O. "Aesthetics of Spectacle, Action and the Notion of Artistic Truth". The Performer: Ilorin Journal of The Performing Arts, vol. 4. (ed) Sunday Enessi Ododo. Department of The Performing Arts, University of Ilorin, 2002. Pp. 63-75

Ejue, Olympus. "Redeeming the Nigerian Identity on Screen: Facing the $21^{\text {st }}$ Century Challenges of Screen Directing in the Theatre Arts Curriculum in Nigeria”. International Journal of Sustainable Development. Vol. 1, No. 3, 2008. Pp.167-170

Inyang, Ofonime. "Script Analysis and Creative Intervention in Play Making: My Experience in "Directing and Stagecraft" Script Understanding, Analysis, Interpretation for Performance. (ed) Effiong Johnson. Ghana: University of Cape Coast Press, 2013.

Johnson, Effiong. Vision towards a Mission: The Art of Interpretative Directing. Lagos: Concept Publications Limited, 2003.

Kamien, Roger. Music: An Appreciation. New York: McGrawHill, 2006 
Nyatuame, Promise Nyatepeh and Bello, Madinatu. "Subverting Audiences' Expectation: Stage Interpretation of Osofisan's Dramaturgy in Altine's Wrath".Script Understanding, Analysis, Interpretation for Performance. (ed) Effiong Johnson. Ghana: University of Cape Coast Press, 2013.

Nketia, Kwabena J. H. "Fela Sowande World Music: A Memorial Lecture" African Art Music in Nigeria: Fela Sowande Memorial. (ed) M. A. Omibiyi Obidike. Ibadan: StirlingHorden Publishers (Nig) Ltd, 2001.

Pavis, Patrice. "The Intercultural Performance Reader". Routledge. 1996

Yerima, Ahmed. Basic Techniques in Playwriting. Ibadan: Kraft Books Limited, 2003 